\title{
Experimental Evaluation of the Mobility Profile of Enhanced Oil Recovery Gases
}

\author{
Ofasa Abunumah, Priscilla Ogunlude, Edward Gobina* \\ Centre for Process Integration and Membrane Technology, School of Engineering, Robert Gordon University, Aberdeen, UK \\ Email: *e.gobina@rgu.ac.uk
}

How to cite this paper: Abunumah, $\mathrm{O}$. Ogunlude, P. and Gobina, E. (2021) Experimental Evaluation of the Mobility Profile of Enhanced Oil Recovery Gases. Advances in Chemical Engineering and Science, 11, 154-164.

https://doi.org/10.4236/aces.2021.112010

Received: March 9, 2021

Accepted: April 9, 2021

Published: April 12, 2021

Copyright $\odot 2021$ by author(s) and Scientific Research Publishing Inc. This work is licensed under the Creative Commons Attribution International License (CC BY 4.0).

http://creativecommons.org/licenses/by/4.0/

\begin{abstract}
The mobility profiles of gases used in enhanced oil recovery (EOR) have been thoroughly investigated through the coupling operations of data mining of oilfield data and experimental data analyses. Mobility as an EOR objective function has not been previously applied to characterize potential reservoirs for EOR selection and application, even though it is a robust combinatorial function that benefits from two petrophysical variables, permeability and viscosity. The data mining approach identified mobility as a reliable objective function for reservoir characterisation. The data distribution and clustering results indicate that Gas EOR reservoirs have relatively higher mean mobility than Thermal, Microbial and Chemical EOR reservoirs. The experimental approach investigated EOR gases, $\mathrm{CO}_{2}, \mathrm{CH}_{4}, \mathrm{~N}_{2}$, and Air. A modified Darcy Equation of State for gas flow through porous media was applied to evaluate which gas would competitively attain the oil displacement optimisation criterion for mobility ratio, $M \leq 1$. Coupling the data mining with the experimental data results reveals that gas reservoirs can be further categorized by mobility. $\mathrm{CH}_{4}(18.16 \mathrm{mD} / \mathrm{cp})$ was observed to have the highest mobility followed by Air $(14.60 \mathrm{mD} / \mathrm{cp}), \mathrm{N}_{2}(13.61 \mathrm{mD} / \mathrm{cp})$, and $\mathrm{CO}_{2}(12.96 \mathrm{mD} / \mathrm{cp})$. The gas mobility order significantly corresponds with the mobility distribution of reservoirs that implemented gas EOR processes. It was concluded that $\mathrm{CO}_{2}$ offers relatively lower mobility, therefore, it is the most competitive EOR gas to approach the mobility ratio criterion of unity or less.
\end{abstract}

\section{Keywords}

Mobility, Viscosity, Permeability, Oil, Gas, Reservoir Characterization, EOR Displacement

\section{Introduction}

One of the key objectives of reservoir engineering is to identify which Enhanced 
Oil Recovery (EOR) process is capable of displacing and producing the most oil. For over 6 decades, gases such as $\mathrm{CO}_{2}, \mathrm{CH}_{4}, \mathrm{~N}_{2}$, and Air have been injected into reservoirs to displace trapped oil ([1] [2] [3] [4] [5]). However, different gases may exhibit certain flow pressure, volume, temperature (PVT) behaviour that could improve or inhibit their EOR potential and efficiency. Therefore, understanding the behaviour of the respective EOR gases would enable engineers to effectively compare their EOR suitability and oil recovery prospect in a reservoir of interest. Consequently, this study aimed to evaluate and identify the competitiveness of EOR gases in displacing trapped oil.

The state of art of gas EOR also indicates that several authors have investigated different parameters that affect oil recovery. References [1] [2] [3] [4] have indicated that relative mobility and viscosity ratios are essential factors to be considered in displacing trapped oil. Several authors have statistically applied different petrophysical parameters and properties to characterise EOR reservoirs and evaluate their effect on the application and performances of EOR technologies. Reference [4] [6]-[13] have mentioned parameters such as permeability, $\mathrm{API}^{\circ}$ gravity and viscosity as suitable parameters for characterising EOR reservoirs. Few authors also included porosity and reservoir thickness as useful parameters ([5] [14]-[19]). In all these EOR criteria, the authors have not investigated the effect of combinatorial quantities, such as mobility, momentum and transmissibility, in characterising EOR reservoirs and screening criteria. Although some other authors have carried out experiments to evaluate gas EOR potential. Such authors include [20]-[25]. However, their studies were conducted on a single or two gases basis (usually $\mathrm{CH}_{4}$ or $\mathrm{CO}_{2}$ ), thereby missing the opportunity for comparing and contrasting the broad spectrum of EOR gases with respect to gas properties, such as viscosity and molecular weight, and reservoir parameters, such as pore size and heterogeneity and mobility. There is no study robust enough to compare the four common EOR gases on these fronts. Therefore, it is imperative to study these two areas of EOR with respect to the relative performance of the four gases used in EOR projects and the mobility profile of the reservoirs they will be applied to. Consequently, this study aims to tackle the knowledge gap and provide statistical and experimental solutions in EOR gas selection, application and potential.

Two empirical approaches have been applied in the evaluation. These are data mining and experimental methods as used by authors such as [1] [2] [8] [26].

\section{Approach 1: Oilfield Data Analyses}

Data mining tools were applied on 365 EOR projects to identify critical EOR and reservoirs parameters that can be used to characterise EOR reservoirs and facilitate the design of laboratory experiments to evaluate EOR gases competitiveness. The benefit of this approach is that it provides insight into the state of the art of EOR technologies across the world and transfer trends from field operation to design laboratory experiments. Information from the data mining phase was 
useful in executing the experimental phase. This data mining technique has been effectively applied in previous work by authors such as [2].

\section{Data Mining Results and Discussions}

Reference [8] [17] and [18], have mentioned API gravity, viscosity, permeability, and depth as engineering quantities for evaluating EOR process competitiveness. It was however observed through data mining that intrinsic mobility $\mathrm{M}_{i}$ was a more robust reservoir factor for characterising EOR reservoirs and evaluating EOR applicability and potential. This factor is derived from Equation (1). Unlike the other parameters, mobility is a combinatorial quantity that combines a rock parameter (permeability $K_{i}, \mathrm{mD}$ ) and a fluid property (dynamic viscosity $\mu_{i}, \mathrm{cp}$ ). Where " $P$ " can be gas or oil fluid, the mobility of the fluid and reservoir system is given as:

$$
M_{i}=\frac{K_{i}}{\mu_{i}}=\left(\frac{K}{\mu}\right)_{i}
$$

The Mobility equation in Equation (1) was applied to the collated field data to generate reservoir characterization clusters in Figure 1. It is observed that EOR reservoirs form different clusters around four EOR technologies. It also reveals that the mobility ratio distribution for gas EOR has relatively higher mean values $(628 \mathrm{D} / \mathrm{cp})$ than the other EOR technologies, such as Chemical $(36.36 \mathrm{mD} / \mathrm{cp})$, Thermal (11.98 mD/cp) and Microbial EOR (7.31 mD/cp) technologies. The implication is that the most applicable EOR methods for such reservoirs are within the Gas EOR technology domain.

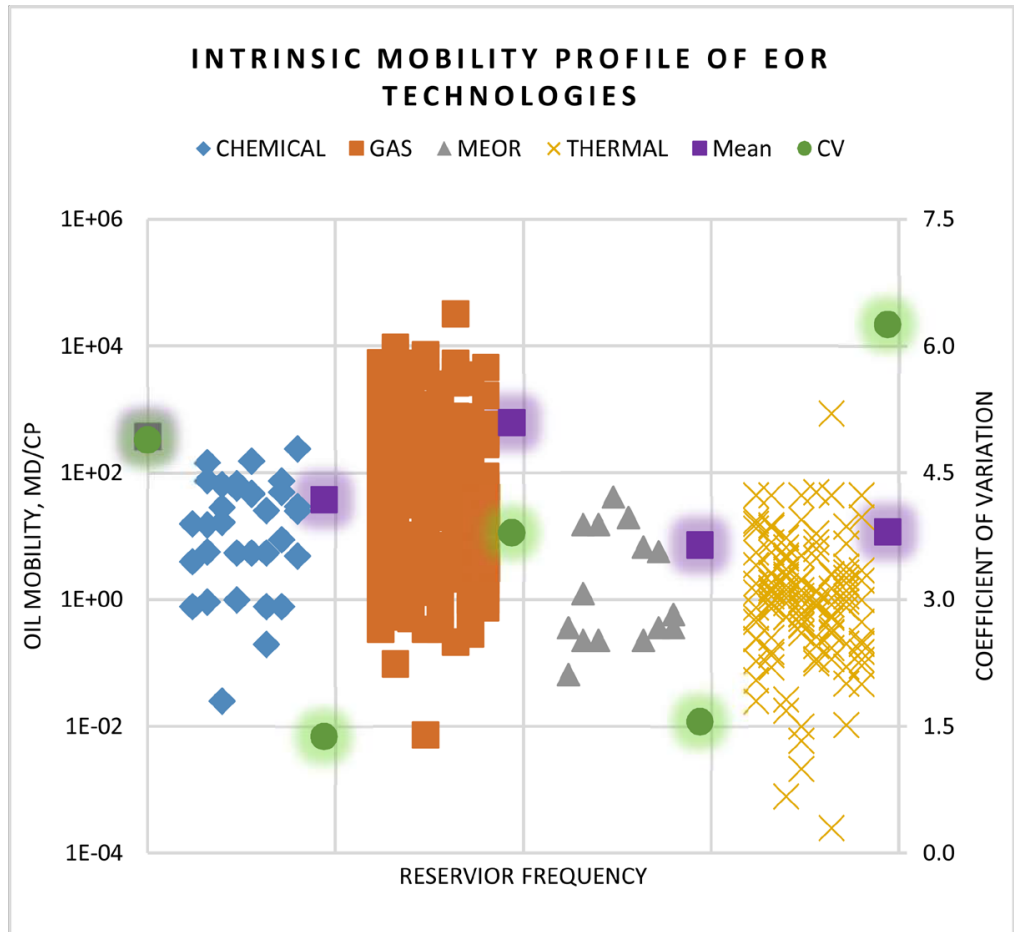

Figure 1. Characterisation of global EOR reservoirs by the intrinsic mobility of oil. 
However, gas EOR technology has more than one method (Miscible and Immiscible) and gases $\left(\mathrm{CO}_{2}, \mathrm{CH}_{4}, \mathrm{~N}_{2}\right.$, and Air). Consequently, the next stage of the study was to identify the characterisation of the reservoirs and the competitiveness of the gases with respect to immiscible Gas EOR technology.

Reference [2] stated that EOR displacement efficiency is based on the dimensionless quantity known as Relative Mobility Ratio, $M$. For immiscible gas EOR, $M$ is the ratio of oil mobility, $M_{o}$, to gas mobility, $M_{g}$ ([27] [28] [29]), this is shown in Equation (2).

$$
M=\frac{M_{\text {displaced }}}{M_{\text {displacing }}}=\frac{M_{o}}{M_{g}}=\left(\frac{\left(\frac{K}{\mu}\right)_{o}}{\left(\frac{K}{\mu}\right)_{g}}\right)
$$

Reference [30] [31] and Warner, and Holstein (2007) and Muggeridge et al., (2014) emphasized that to achieve stable and favourable oil displacement, $\mathrm{M}$ must be $\leq 1$. When $M$ is $>1$, it implies that the displacing fluid (gas) is more mobile than the displaced fluid (oil). This will cause the oil to be bypassed by the stream of gas, thereby creating an unstable front, undesired viscous fingering, resulting in significantly poor sweep efficiency ([1] [31] [32] [33]). Figures 2(a)-(c) show three scenarios of oil-gas mobility ratios. The gas is injected into the injection well, oil and gas are expected at the producer well. A stable contour in A and B optimize oil production, while Figure 2(c) maximizes gas production because of the relatively higher mobility ratio $(M=2.40)$.

Consequent to Figure 1 and Figure 2(a) and Figure 2(b), Approach two of this study was therefore designed to identify the gas that would comparatively approach $\mathrm{M} \leq 1$. A modified Darcy equation of state (Equation (3)) for gas radial flow at varying temperature was used to derive intrinsic mobility of the respective gases.
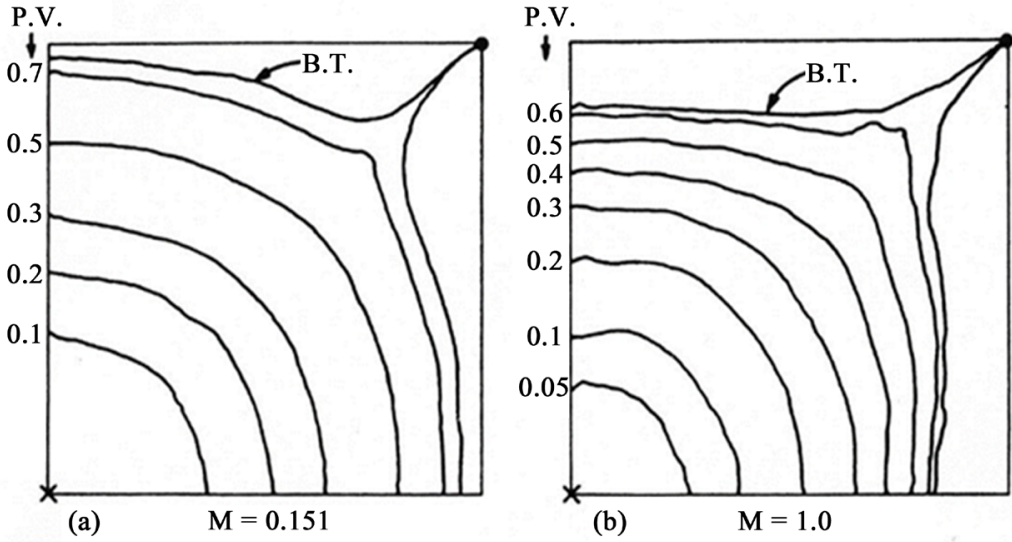

(b)

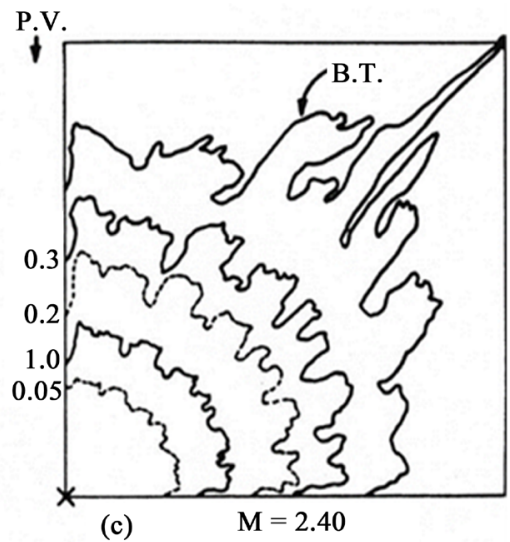

(c)
- PRODUCING WELL $\times$ INJECTION WELL
P.V. = PORE VOLUME INJECTED B.T. $=$ VREAKTHROUGH

Figure 2. Areal view of the effect of mobility ratio on gas/oil displacement process [30]. 


$$
Q_{s t d}=920 \frac{K}{\mu} \frac{\left(P_{1}^{2}-P_{2}^{2}\right)}{\ln \frac{r_{1}}{r_{2}}} \frac{M C_{p}}{\left(\mathrm{H}+M C_{p} T_{1}\right)}
$$

In a comparative study to investigate energy transfer between injected gases at $T_{1}$, and core sample (or reservoir) possessing heat energy, $H$, the First and Second thermodynamics laws lend themselves to understanding how the energy transfer could be described with respect to specific heat at constant pressure, $C_{p}$, of the respective gases. The temperature of the injected gases, $T_{1}$, could be considered as a convenient constant injection reference temperature (standard, 273 $\mathrm{K}$, or normal, $293 \mathrm{~K}$ ) and the heat supplied to the core sample can be maintained as a steady heat supply. Therefore, without loss of generality, $T_{1}$ and $H$ can be eliminated as a constant in Equation (3), thereby reducing the equation to an apparent flow shown in Equation (4):

$$
Q_{\text {std-apparent }}=\frac{K}{\mu} M C_{p}\left(P_{1}^{2}-P_{2}^{2}\right)
$$

Consequently, the respective intrinsic mobility of the gases can be expressed as:

$$
\mathrm{M}_{i}=\left(\frac{K}{\mu}\right)_{i}=\left(\frac{Q_{\text {std-apparent }}}{M C_{p}\left(P_{1}^{2}-P_{2}^{2}\right)}\right)_{i}
$$

\section{Approach 2: Laboratory Experimental Analyses}

Laboratory PVT experiment and analyses in analogous reservoir conditions were carried out using mobility as the EOR objective function as identified in Approach one.

\subsection{Experimental Materials and Equipment Set up}

1) Five Core Samples with pore sizes: $15 \mathrm{~nm}(\mathrm{x} 2), 200 \mathrm{~nm}(\mathrm{x} 1)$ and $6000 \mathrm{~nm}(\mathrm{x} 2)$.

2) Four EOR Gases: $\mathrm{CH}_{4}, \mathrm{~N}_{2}, \mathrm{Air}, \mathrm{CO}_{2}$.

3) Figure 3 shows the equipment and setup of the experiment.

\subsection{Experimental Procedure}

1) The core holder was heated to the desired temperature and thermal stability.

2) Gas was supplied into the core holder set up to the desired pressure.

3) Flow rate readings were recorded at a steady state.

4) This procedure is repeated at pressure intervals of 0.40 bar until the maximum pressure ( 3 bar) and temperatures 293, 323, 373, 423, 473 and $673 \mathrm{~K}$ are reached.

\subsection{Experimental Results and Discussions}

Experimental data were applied to Equation (5) to generate the intrinsic mobilities of the respective gases. The data so generated was used to make cluster plots. 


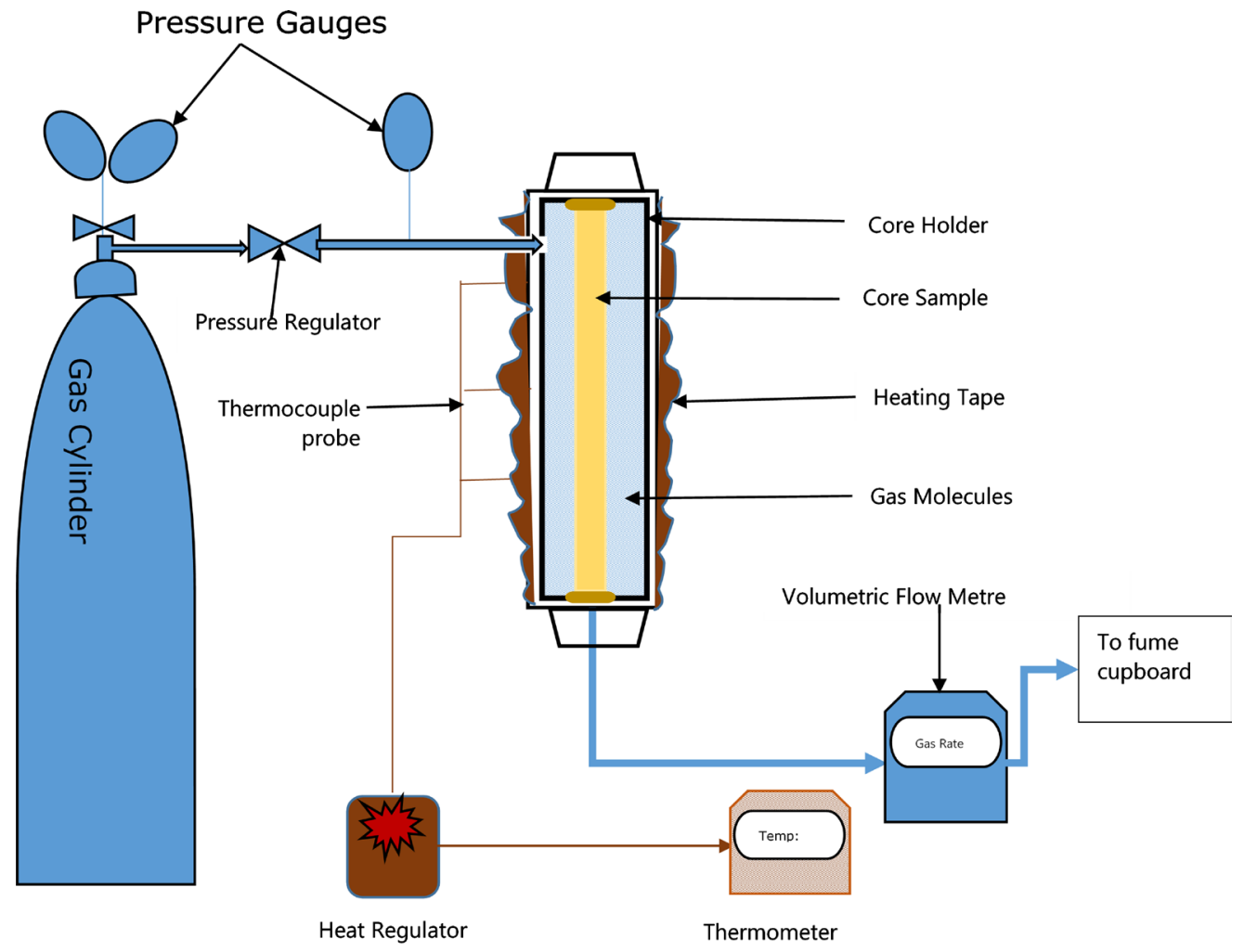

Figure 3. A schematic of experimental equipment and set up.

The field and experimental results were compared and summarized in Figure 4(a) and Figure 4(b). It was discovered from the clusters that reservoirs with relatively high intrinsic mobility $(>1650 \mathrm{mD} / \mathrm{cp})$ implemented $\mathrm{CH}_{4}(18.16$ $\mathrm{mD} / \mathrm{cp})$ gas EOR. In contrast, reservoirs with relatively low mobility $(<121$ $\mathrm{mD} / \mathrm{cp})$ implemented $\mathrm{CO}_{2}(12.97 \mathrm{mD} / \mathrm{cp})$ gas EOR. The cluster for each of the gases in Figure 4(b) is seen to have three sub-clusters. The topmost clusters in Figure 4(b) significantly correspond with the order of the clusters in Figure 4(a). Therefore, the apparent intrinsic mobilities in Figure 4(b) can be said to correspond with and validates the experimental mobility of EOR gases in Figure 4(a). $\mathrm{CH}_{4}(18.16 \mathrm{mD} / \mathrm{cp})$ was observed to have the highest mobility followed by Air ( $14.60 \mathrm{mD} / \mathrm{cp}), \mathrm{N}_{2}(13.61 \mathrm{mD} / \mathrm{cp})$, and $\mathrm{CO}_{2}(12.96 \mathrm{mD} / \mathrm{cp})$.

These results are very revealing because this relationship has not been reported in journals previously. Although the mobilities clusters of Figure 4(a) and Figure 4(b) correspond, however, based on the relative mobility ratio criteria earlier stated by [1] [31] [32] and [33], it is expected that $\mathrm{CO}_{2}$ will be the most likely gas to approach the favourable condition of $\mathrm{M} \leq 1$, therefore the most competitive EOR gas. It is also noted that the CVs for the graphs are fairly opposite in direction. The gas EOR reservoirs CVs form a convex profile, while the displacing gas CVs form a concave profile. This suggests that in the implementation of gas EOR injection in reservoirs, the observed sensitivity of the respective gas mobilities in the laboratory may not have a significant effect on implementation. 
EOR process sensitivity to mobility can be compared in Figure 5 . The relative magnitude of the field and experiment data indicates the field and experimental

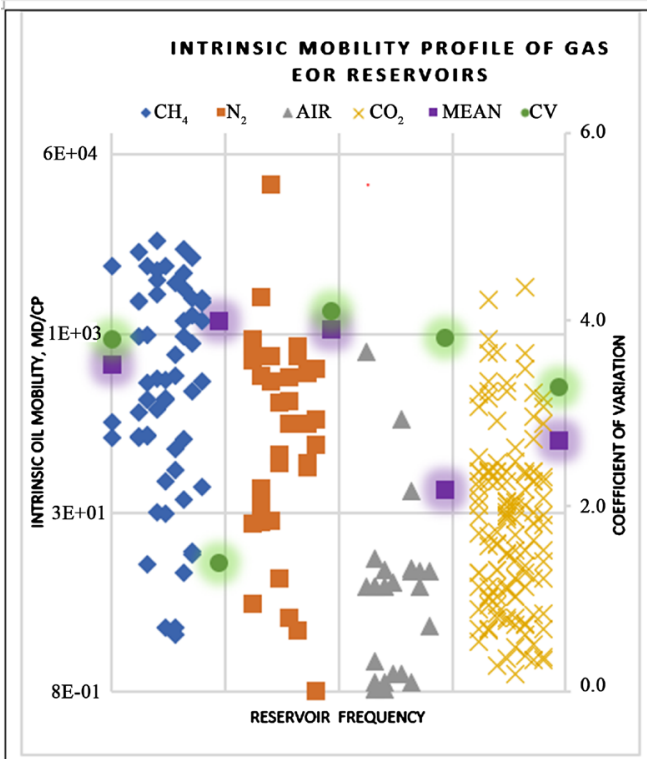

a) The reservoirs are characterised by intrinsic mobility, such that $\mathrm{CH}_{4}$ clusters settles at the higher mobility reservoirs than $\mathrm{CO}_{2}$. The order of the $\mathrm{CV}$ distribution indicates $\mathrm{CH}_{4}$ is the most likely to be perturbed mobility variation and $\mathrm{N}_{2}$ is the least perturbed

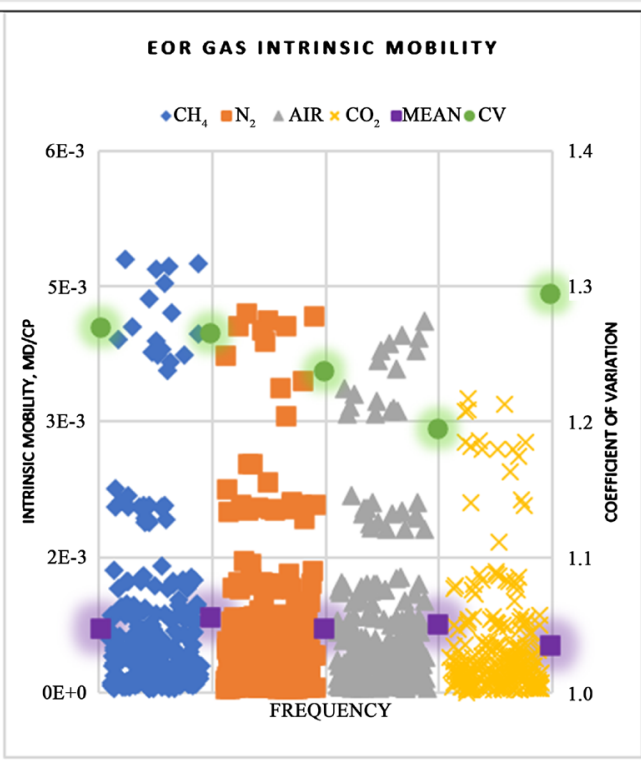

b) The clusters are well defined and distinct, indicating that EOR gases can be characterised by mobility. The order of magnitude here is similar to that of reservoir oil mobility. This is implying a proportional correlation between gas and reservoir oil mobilities exists, although the order of the gas and oil CVs is shown to be inversely related.

Figure 4. Graphs comparing and contrasting the mobility profiles of global gas EOR reservoirs and projects (a) and the Mobility profile of EOR gases (a).

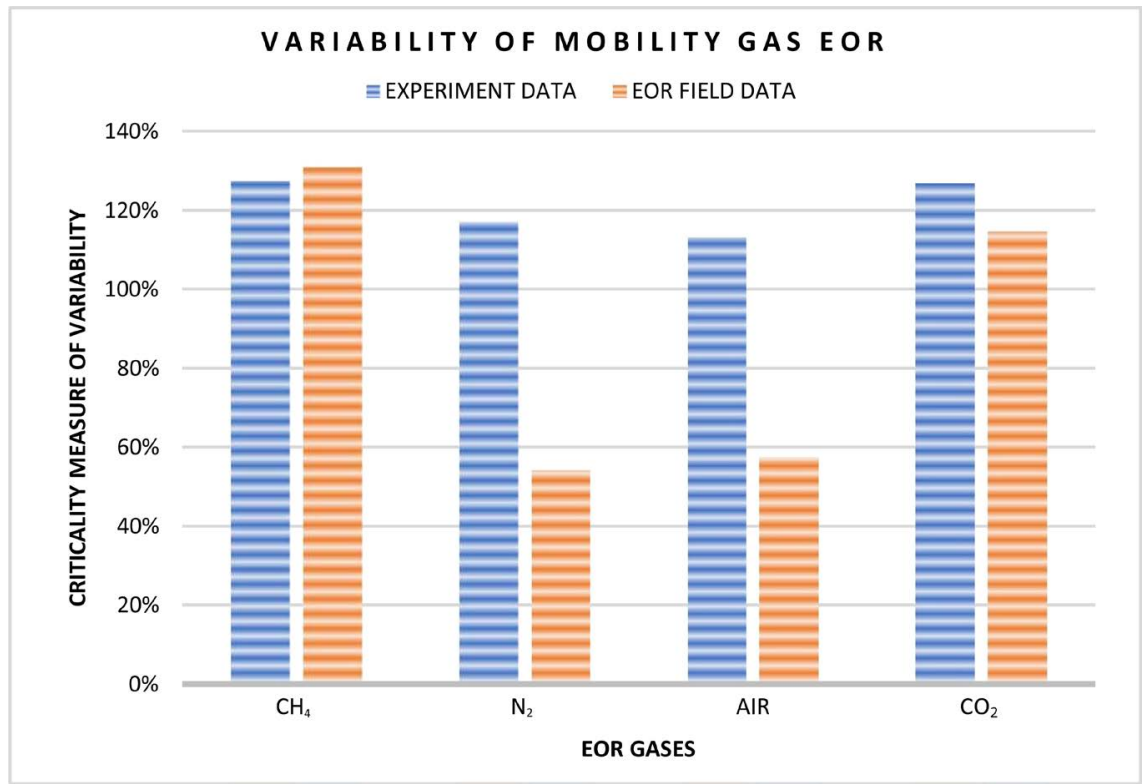

Figure 5. Variability of mobility in the field and experimental data. 
data significantly validated each other. Figure 5 shows that $\mathrm{N}_{2}$ and Air are the most sensitive to mobility by virtue of their relatively low variability values.

\section{Conclusions}

Field and laboratory experimental data have been successfully applied to investigate the competitiveness of EOR gases based on the identified combinatorial objective function called intrinsic mobility.

It has been demonstrated that EOR projects and reservoirs can be characterized and evaluated based on intrinsic mobility. This characterisation is also reflected in the EOR gases commonly injected to displace trapped oil. The experimental results significantly validated the mobility profile observed in the field mobility clusters.

For the fours EOR gases, the experiments confirmed that $\mathrm{CO}_{2}$ is the most competitive gas followed by $\mathrm{N}_{2}$, Air and $\mathrm{CH}_{4}$.

\section{Conflicts of Interest}

The authors declare no conflicts of interest regarding the publication of this paper.

\section{References}

[1] Hamid, S.A.A. and Muggeridge, A. (2018) Viscous Fingering in Reservoirs with Long Aspect Ratios. Society of Petroleum Engineers Improved Oil Recovery Conference, Tulsa, April 2018, Article No. SPE-190294-MS.

https://doi.org/10.2118/190294-MS

[2] Hamid, S.A. and Muggeridge, A.H. (2018) Analytical Solution of Polymer Slug Injection with Viscous Fingering. Computational Geosciences, 22, 711-723. https://doi.org/10.1007/s10596-018-9721-0

[3] Todd Hoffman, B. (2012) Comparison of Various Gases for Enhanced Recovery from Shale Oil Reservoirs. Society of Petroleum Engineers Improved Oil Recovery Symposium, Tulsa, April 2012. Article No. SPE-154329-MS. https://doi.org/10.2118/154329-MS

[4] Alvarado, V. and Manrique, E. (2010) Enhanced Oil Recovery: An Updated Review. Energies, 3, 1529-1575. https://doi.org/10.3390/en3091529

[5] Gbadamosi, A.O., Kiwalabye, J., Junin, R. and Augustine, A. (2018) A Review of Gas Enhanced Oil Recovery Schemes Used in the North Sea. Journal of Petroleum EXploration and Production Technology, 8, 1373-1387. https://doi.org/10.1007/s13202-018-0451-6

[6] Brashear, J.P. and Kuuskraa, V.A. (1978) The Potential and Economics of Enhanced Oil Recovery. Journal of Petroleum Technology, 30, 12341-1239.

https://doi.org/10.2118/6350-PA

[7] Goodlett, G.O., Honarpour, M.M., Chung, F.T. and Sarathi, P.S. (1986) The Role of Screening and Laboratory Flow Studies in EOR Process Evaluation. Society of Petroleum Engineers Rocky Mountain Regional Meeting, Billings, May 1986, Article No. SPE-15172-MS. https://doi.org/10.2118/15172-MS

[8] Taber, J.J., Martin, F.D. and Seright, R.S. (1997) EOR Screening Criteria Revisited-Part 2: Applications and Impact of Oil Prices. Society of Petroleum Engineers 
Improved Reservoir Engineering, 12, 199-206. https://doi.org/10.2118/39234-PA

[9] Taber, J.J., Martin, F.D. and Seright, R.S. (1997) EOR Screening Criteria Revisited-Part 1: Introduction to Screening Criteria and Enhanced Recovery Field Projects. SPE Reservoir Engineering, 12, 189-198.

https://doi.org/10.2118/35385-PA

[10] Alvarado, V. and Manrique, E. (2010) Chapter 8: EOR's Current Status. In: Alvarado, V. and Manrique, E., Eds., Enhanced Oil Recovery, Gulf Professional Publishing, Boston, 133-156. https://doi.org/10.1016/B978-1-85617-855-6.00014-0 https://www.sciencedirect.com/science/article/pii/B9781856178556000140

[11] Alvarado, V. and Manrique, E. (2010) Enhanced Oil Recovery: Field Planning and Development Strategies. Gulf Professional Publishing, Boston.

https://doi.org/10.1016/C2009-0-30583-8

[12] Karović-Maričić, V., Leković, B. and Danilović, D. (2014) Factors Influencing Successful Implementation of Enhanced Oil Recovery Projects. Podzemni radovi, 22, 41-50. https://doi.org/10.5937/podrad1425041K

[13] Bachu, S. (2016) Identification of Oil Reservoirs Suitable for $\mathrm{CO}_{2}$-EOR and $\mathrm{CO}_{2}$ Storage (CCUS) Using Reserves Databases, with Application to Alberta, Canada. International Journal of Greenhouse Gas Control, 44, 152-165. https://doi.org/10.1016/j.ijggc.2015.11.013

[14] Guerillot, D.R. (1988) EOR Screening with an Expert System. Petroleum Computer Conference, San Jose, June 1988, Article No. SPE-17791-MS.

https://doi.org/10.2118/17791-MS

[15] Surguchev, L. and Li, L. (2000) IOR Evaluation and Applicability Screening Using Artificial Neural Networks. SPE/DOE Improved Oil Recovery Symposium, Tulsa, 3-5 April 2000, Article No. SPE-59308-MS. https://doi.org/10.2118/59308-MS

[16] Trujillo Portillo, M.L., Mercado Sierra, D.P., Maya, G.A., Castro Garcia, R.H., Soto, C.P., Perez, H.H. and Gomez, V. (2010) Selection Methodology for Screening Evaluation of Enhanced-Oil-Recovery Methods. Society of Petroleum Engineers Improved Latin American and Caribbean Petroleum Engineering Conference, Lima, December 2010, Article No. SPE-139222-MS.

https://doi.org/10.2118/139222-MS

[17] Saleh, L.D., Wei, M. and Bai, B. (2014) Data Analysis and Updated Screening Criteria for Polymer Flooding Based on Oilfield Data. SPE Reservoir Evaluation \& Engineering, 17, 15-25. https://doi.org/10.2118/168220-PA

[18] Kang, P.S., Lim, J.S. and Huh, C. (2014) Screening Criteria for Application of EOR Processes in Offshore Fields. The 24th International Ocean and Polar Engineering Conference, Busan, 15-20 June 2014, 159.

[19] Nageh, M., El Ela, M.A., El Tayeb, E.S. and Sayyouh, H. (2015) Application of Using Fuzzy Logic as an Artificial Intelligence Technique in the Screening Criteria of the EOR Technologies. SPE North Africa Technical Conference and Exhibition, Cairo, September 2015, Article No. SPE-175883-MS.

https://doi.org/10.2118/175883-MS

[20] Gui, B., Yang, Q.Y., Wu, H.J., Zhang, X. and Lu, Y. (2010) Study of the Effects of Low-Temperature Oxidation on the Chemical Composition of a Light Crude Oil. Energy \& Fuels, 24, 1139-1145. https://doi.org/10.1021/ef901056s

[21] Khodaei Booran, S., Upreti, S.R. and Ein-Mozaffari, F. (2016) Enhanced Oil Recovery with Air Injection: Effect of the Temperature Variation with Time. Energy \& Fuels, 30, 3509-3518. https://doi.org/10.1021/acs.energyfuels.5b02661 
[22] Dellinger, S.E., Patton, J.T. and Holbrook, S.T. (1984) $\mathrm{CO}_{2}$ Mobility Control. Society of Petroleum Engineers Journal, 24, 191-196. https://doi.org/10.2118/9808-PA

[23] Jia, H., Yuan, C.D., Zhang, Y., Peng, H., Zhong, D. and Zhao, J. (2012) Recent Progress of High-Pressure Air Injection Process (HPAI) in Light oil Reservoir: Laboratory Investigation and Field Application. Society of Petroleum Engineers Heavy Oil Conference Canada, Calgary, June 2012, Article No. SPE-156974-MS. https://doi.org/10.2118/156974-MS

[24] Masalmeh, S.K., Wei, L. and Blom, C. (2011) Mobility Control for Gas Injection in Heterogeneous Carbonate Reservoirs: Comparison of Foams versus Polymers. Society of Petroleum Engineers Middle East Oil and Gas Show and Conference, Manama, September 2011, Article No. SPE-142542-MS. https://doi.org/10.2118/142542-MS

[25] Li, K. and Horne, R.N. (2001) An Experimental and Analytical Study of Steam/Water Capillary Pressure. SPE Reservoir Evaluation \& Engineering, 4, 477-482. https://doi.org/10.2118/75294-PA

[26] Lacey, M., Hollis, C., Oostrom, M. and Shokri, N. (2017) Effects of Pore and Grain Size on Water and Polymer Flooding in Micromodels. Energy \& Fuels, 31, 9026-9034. https://doi.org/10.1021/acs.energyfuels.7b01254

[27] Fanchi, J. (2010) Integrated Reservoir Asset Management: Principles and Best Practices. Gulf Professional Publishing, Houston. https://doi.org/10.1016/C2009-0-62240-6

[28] Abdus, S. and Ghulam, M.I. (2016) 16-Waterflooding and Waterflood Surveillance. In: Abdus, S. and Iqbal, G.M., Ed., Reservoir Engineering. The Fundamentals, Simulation, and Management of Conventional and Unconventional Recoveries, Gulf Professional Publishing, Amsterdam, 289-312. https://doi.org/10.1016/B978-0-12-800219-3.00016-4

[29] Sheng, J.J. (2011) Mobility Control Requirement in EOR Processes. In: Sheng, J.J., Ed., Modern Chemical Enhanced Oil Recovery. Theory and Practice, Gulf Professional Publishing, Houston, 79-100. https://doi.org/10.1016/B978-1-85617-745-0.00004-8

[30] Warner, H.R. and Holstein, E.D. (2007) Chapter 12: Immiscible Gas Injection in Oil Reservoirs. In: Lake, L.W., Fanchi, J.R., Arnold, K., Clegg, J.D., Holstein, E.D. and Warner, H.R., Eds., Petroleum Engineering Handbook: Reservoir Engineering and Petrophysics, Vol. 5, Society of Petroleum Engineers, 1103-1147

[31] Muggeridge, A., Cockin, A., Webb, K., Frampton, H., Collins, I., Moulds, T. and Salino, P. (2014) Recovery Rates, Enhanced Oil Recovery and Technological Limits. Philosophical Transactions of the Royal Society A: Mathematical, Physical and Engineering Sciences, 372, Article ID: 20120320. https://doi.org/10.1098/rsta.2012.0320

[32] Lyons, W. (2009) Working Guide to Reservoir Engineering. Gulf Professional Publishing, Houston.

[33] Lyons, W.C. and Plisga, G.J. (2011) Standard Handbook of Petroleum and Natural Gas Engineering. 2 Edition, Elsevier, Gulf Professional Publishing, Burlington. 


\section{Nomenclature}

$Q_{g}=$ gas flow rate $\left(\mathrm{cm}^{3} \cdot \mathrm{sec}^{-1}\right)$;

$K_{g}=$ gas permeability $(\mathrm{mD})$;

$K_{=}=$oil permeability $(\mathrm{mD})$;

$\mu_{g}=$ gas viscosity (cp);

$\mu_{0}=$ oil viscosity (cp);

$P_{1}$ and $P_{2}=$ Inlet and outlet pressure (atm);

$\mathrm{M}=$ Molar mass $(\mathrm{g} / \mathrm{mol})$;

$\mathrm{C}_{\mathrm{p}}=$ specific heat-constant pressure;

$h=$ height of core sample $(\mathrm{cm})$;

$r_{1}$ and $r_{2}=$ core inner and outer diameter $(\mathrm{cm})$;

' $\mathrm{i}$ ' = fluid such as gas and oil;

$T_{1}=$ Inlet temperature of gas;

PVT $=$ Pressure, Volume and Temperature . 